With 2 plates

Printed in Great Britain

\title{
The Preparation and Biochemical Properties of Mitochondria from Neurospora crassa
}

\author{
By D. O. HALL* AND J. W. GREENAWALT \\ Department of Physiological Chemistry, Johns Hopkins School of Medicine, \\ Baltimore, Maryland
}

(Accepted for publication 22 March 1967)

SUMMARY

Mitochondria were prepared in large quantities from Neurospora crassa by grinding hyphae with glass beads in an Eppenbach Micro-mill. Observation in the electron microscope indicated that some of the isolated mitochondria were probably damaged during preparation. Nevertheless, the crude mitochondrial fraction was capable of coupling phosphorylation to the oxidation of seven different substrates tested. The $\mathrm{P}: \mathrm{O}$ ratio obtained with succinate ranged from 0.7 to $\mathrm{I} \cdot 3$ in different experiments with different mitochondrial preparations, but only low respiratory control ratios were observed. The effects of common inhibitors of oxidative phosphorylation were similar to those reported with mammalian mitochondria. In addition, ATPase and ATP-Pi exchange activities, as well as ion accumulation, were measured in the Neurospora mitochondria. The use of a 'preparation' medium containing sucrose, $0.25 \mathrm{M}$; EDTA, $0.005 \mathrm{M}(\mathrm{pH} 7.0)$; bovine serum albumin $(0.15 \%$, $\mathrm{w} / \mathrm{v})$ was necessary to obtain these results.

\section{INTRODUCTION}

The filimentous fungi contain intracytoplasmic organelles which have the basic structural characteristics of mammalian mitochondria (Moore \& McAlear, 1963; Tsuda, I956; Shatkin \& Tatum, 1959). In fact, the distinct mitochondria and nuclei in the 'higher' fungi cytologically distinguish these microbes from the more primitive protists (Moore \& McAlear, 1963; Iterson, 1965). Only recently, however, have discrete subcellular particles capable of effecting oxidative phosphorylation been successfully isolated from these organisms (Vitols \& Linnane, 196I ; Hall \& Greenawalt, 1964; Ohnishi, Kawaguchi \& Hagihara, I966). In order to isolate intact mitochondria from Neurospora crassa the thick resistant heteropolysaccharide-containing cell walls of this organism must be broken or removed without extensively damaging the mitochondria. Because of differences in morphology and chemical composition, not all forms of $N$. crassa are equally susceptible to disruption by a particular method, i.e. some procedures useful in breaking long vegetative hyphae are ineffective in disrupting the smaller more spherical conidia. Luck (1963) isolated mitochondria from hyphae by grinding with sand in a mortar and pestle, but only relatively small quantities of these vegetative cells can be disrupted easily by this procedure. The study of oxidative phosphorylation by mitochondria isolated from cells broken in this manner has not

* Present address: Department of Botany, King's College, London. 
been reported. Mitochondria have been prepared from conidia and from hyphae of Neurospora crassa which were converted enzymically to 'protoplasts' and then lysed (Weiss, I965). The long incubation time (IO-I5 hr) required for digestion of the cell wall makes this procedure unsuitable for many studies; mitochondria from a given form, e.g. conidia, may be structurally or functionally altered during long incubation periods. Similar procedures have been used, however, to produce spheroplasts of yeast cells (Duell, Inoue, \& Utter, 1964) from which functional mitochondria have been obtained.

This paper describes a procedure for preparing mitochondria from Neurospora crassa which are capable of coupling phosphorylation to the oxidation of several substrates. The data reported here were obtained in studies utilizing mitochondria isolated in large quantities from 2-day hyphae broken by high-speed homogenization in the presence of glass beads. This procedure made it possible also to compare oxidative phosphorylation by mitochondria from conidia, germinating conidia and hyphae (these latter results will be reported elsewhere). A brief report of the present work has been communicated (Hall \& Greenawalt, I964).

\section{METHODS}

Growth of Neurospora crassa and production of conidia. Stock cultures of Neurospora crassa, wild-type strain SY 7 A (obtained from the Fungal Genetic Stock Centre, Dartmouth College, Hanover, N.H., U.S.A.) were maintained on $2 \%$ agar slopes of the minimal medium described by Wainwright (1959) and stored at $5^{-} 8^{\circ}$ until used. It is essential for biochemical studies to have a supply of conidia available: $(a)$ as a source from which mitochondria can be prepared directly, or $(b)$ as inocula for producing germinating conidia or hyphae, but the formation of mature conidia by $N$. crassa requires 7-9 days. However, it was found in preliminary studies that conidia harvested and suspended in distilled water remained viable for at least 7 days with no change in the rate or percentage of germination when stored under aseptic conditions at $4^{\circ}$. Therefore, each week 20 agar slopes of Wainwright's conidiation medium (1959) were inoculated and grown at room temperature under fluorescent lamps to induce conidiation; conidia produced on these slopes were then used for the subsequent largescale production of conidia. At the end of 4-5 days conidia from each of 16 slopes were scratched with a loop from the surface of the slopes into $10 \mathrm{ml}$. sterile distilled water. The conidial suspensions were combined and ultrasonically treated for $2 \mathrm{~min}$. in a Di Sontegrator System 40 (Ultrasonic Industries, Albertson, L.I., New York, U.S.A.) to break up conidial clumps. The suspension was filtered through cheesecloth and $5 \mathrm{ml}$. was added to each of sixteen, $2 \cdot 81$. Fernbach flasks containing $500 \mathrm{ml}$. of Wainwright's solid medium (1959). The conidial inoculum was spread evenly over the agar surface, the flasks wrapped with aluminium foil to protect from light and the cultures incubated for 3 days at $30^{\circ}$. The wrappings were then removed and incubation continued at room temperature under continuous light for an additional $4-6$ days. To allow adequate gaseous exchange for optimal conidiation and still maintain aseptic conditions, covers for these flasks were made of two layers of cheesecloth, one layer of non-absorbent cotton-wool, one layer of cheesecloth, another layer of cotton-wool and finally a layer of cheesecloth; these covers were fastened firmly in place with rubber bands. 
Conidia were harvested by adding Io sterile marbles (10-15 mm. diam.) and $200 \mathrm{ml}$. sterile distilled water containing 3 drops of silicone antifoam type B (Dow Corning Corp., Midland, Mich., U.S.A.) as a wetting agent, to each flask. The flasks were shaken by hand to remove the mat of growth from the agar surface. The suspensions were combined, filtered through four layers of cheesecloth to remove bits of hyphae and ultrasonically treated (as above) for 2 min. The dark orange conidial suspension was stored at $4^{\circ}$ for no longer than I week before use. Sixteen Erlenmeyer flasks yielded $2 \cdot 51$. of conidial suspension containing about $2 \times 10^{8}$ conidia $/ \mathrm{ml}$.

Growth of hyphae. Hyphae were grown by aseptically transferring about $50 \mathrm{ml}$. of the conidial suspension containing about $10^{10}$ conidia $\left(50 \mathrm{ml} \times 2 \times 10^{8}\right.$ conidia $/ \mathrm{ml}$.) into $500 \mathrm{ml}$. of Vogel's complete medium (1956) +3 drops of silicone antifoam in a 21 . Erlenmeyer flask. Cultures were incubated for 2 days at $30^{\circ}$ on a rotary shaker (about $265 \mathrm{rev}$./min.).

Preparation of mitochondria. Quantities of mitochondria sufficient to do numerous biochemical assays were obtained from I 1. of a 2-day culture of Neurospora crassa. The hyphae were collected (centrifugation at $500 \mathrm{~g}$ for $5 \mathrm{~min}$.), washed at $0-4^{\circ}$ by suspension and centrifugation in distilled water, and finally suspended in $500 \mathrm{ml}$. of a 'preparation' medium which consisted of: sucrose, 0.25 M; EDTA, 0.005 M (pH 7.0); and bovine serum albumin (BSA), $0.15 \%(\mathrm{w} / \mathrm{v})$. All subsequent operations were done in the cold $\left(0-4^{\circ}\right)$. To a sample $(250 \mathrm{ml}$.) of the hyphae suspended in preparation medium were added $500 \mathrm{~g}$ acid-washed glass beads $(0.2 \mathrm{~mm}$. diam.) and 4 drops of silicone antifoam; the mixture of beads and organism were poured into a chilled Eppenbach Micro-mill, Model MV-6-3 (Gifford-Wood Co., Hudson, N.Y., U.S.A.) and ground at maximal speed for $\mathrm{I}$ min. at a gap setting of $\mathrm{I} / 30,000 \mathrm{in}$. The ratio of liquid volume to bead volume and the time of grinding was carefully standardized to obtain adequate cell breakage and subsequent separation of functional mitochondria. Under the conditions outlined here about $75 \%$ of the hyphal cells were disrupted. Broken cells and beads were spun out of the mill, at low speed with the gap completely open, into a large beaker and the contents were allowed to sediment for a few min. The unsedimented material was decanted. The beads were washed twice with preparation medium to remove trapped cellular components and the washes were added to the decanted liquid. The mitochrondria were collected from the decanted liquid by differential centrifugation, as a fraction sedimenting between I $500 \mathrm{~g}$ (Io min.) and $8000 \mathrm{~g}$ ( $30 \mathrm{~min}$.) A second $1500 \mathrm{~g}$ centrifugation before the final sedimentation of the mitochondria at $8000 \mathrm{~g}$ removed additional amounts of contaminating cell wall fragments. The final mitochondrial pellet was suspended in $3-5 \mathrm{ml}$. of preparation medium to give a final concentration of $20-30 \mathrm{mg}$. protein $/ \mathrm{ml}$. All suspensions were made with TenBroeck ground glass homogenizers. The complete preparative procedure required about $2 \cdot 5 \mathrm{hr}$.

Electron microscopy. Samples of intact hyphae, of the crude mitochondrial fractions and of all fractions separated by density gradient centrifugation were fixed with $0.6 \%$ aqueous $\mathrm{KMnO}_{4}$ and 'post-fixed' with $5 \%$ uranyl acetate (North, 196I). The fixed pellets were dehydrated by rapid passage through a cold $\left(-10^{\circ}\right)$ ethanol series and embedded in Epon 8I2 by the method of Luft (196r). Thin sections were cut on a Porter-Blum or an LKB microtome. Sections were not post-stained.

Samples of fractions obtained at different stages during the preparation of mitochondria were negatively stained with I $\%$ potassium phosphotungstate (PTA, $\mathrm{pH} 6.5$ - 
$6.8)$ to determine whether the mitochondria were grossly contaminated with other cellular components. Sections and negatively stained preparations were observed in Siemens Elmiskop I double-condenser electron microscope operated at $80 \mathrm{kV}$. with $50 \mu$ objective apertures.

Biochemical assays. Oxidative phosphorylation was calculated by measuring the respiration manometrically at $25^{\circ}$ (using $5 \mathrm{ml}$. or $15 \mathrm{ml}$. vessels) according to Slater \& Holton (1954) and by determining the amount of inorganic phosphate (Pi) esterified (Gomori 1942). All reaction media used for biochemical assays were at $\mathrm{pH} 6 \cdot 9$.

Respiratory control at $25^{\circ}$ was estimated by the method of Chance \& Williams (I955) with a Clark oxygen electrode.

Difference spectra, from which the content of the cytochromes in the mitochondria was estimated, were obtained by the procedure of King, Nickel \& Jensen (I964) by using a Beckman DK Recording Spectrophotometer.

Continuous sucrose density gradients $(20-65 \%, \mathrm{w} / \mathrm{v} ; 0 \cdot 58-\mathrm{I} \cdot 9 \mathrm{M})$ were prepared with a Buchler Densigrad apparatus (Buchler Instruments, Fort Lee, New Jersey, U.S.A.) by the procedure of Luck (1963) following Britten \& Roberts (I960). The same apparatus was used to collect fractions from the gradient. A sample of the mitochondrial preparation $(0.5-0.9 \mathrm{ml}$.) was layered on the top of a $4.6 \mathrm{ml}$. gradient and centrifuged for $\mathrm{I} \mathrm{hr}$ at $40,000 \mathrm{rev} . / \mathrm{min}$. in a Spinco centrifuge.

The mitochondrial adenosine triphosphatase (ATPase) activity was determined by the release of inorganic phosphate (Cooper \& Lehninger, 1957); the adenosine triphosphate-inorganic phosphate (ATP- $\left.{ }^{32} \mathrm{Pi}\right)$ exchange reaction by the formation of $\mathrm{AT}^{32} \mathrm{P}$ (Wadkins \& Lehninger, I963); calcium accumulation by the disappearance of ${ }^{45} \mathrm{Ca}^{2+}$ from the reaction medium (Rossi \& Lehninger, 1963); the adenosine triphosphate-adenosine diphosphate (ATP-ADP) exchange by the incorporation of ADP-I- ${ }^{14} \mathrm{C}$ into ATP (Wadkins \& Lehninger, I963). The uptake of leucine-I- ${ }^{14} \mathrm{C}$ by mitochondria preparations was estimated by the method of Truman \& Korner (I962).

Protein was estimated usually by the microbiuret method of Goa (I953), but when the high sucrose concentration in fractions from the density gradient was found to interfere, the method of Lowry, Rosebrough, Farr \& Randall (I95I) was used. Crystalline bovine serum albumin served as a standard in these determinations.

\section{RESULTS}

\section{Electron microscopy}

Mitochondria were easily recognized in thin sections of hyphae of Neurospora crassa fixed with $\mathrm{KMnO}_{4}$ + uranyl acetate (Pl. I, fig. I); the cristae were distinct and the basic structural appearance was similar to that typical of mitochondria from other cells. The mitochondrial matrices appeared to have about the same opacity as the cytoplasm, and the cells in general had the diluted appearance characteristic of many cells and tissues fixed with $\mathrm{KMnO}_{4}$. Ribosomes could not be distinguished, probably because the sections were not stained and the contrast was relatively low.

The mitochondrial preparation obtained by differential centrifugation between I $500 \mathrm{~g}$ and $8000 \mathrm{~g}$ contained some contaminating cellular structures but was primarily composed of mitochondria (P1. I, fig. 2). Much of the contamination was cell wall material which was readily identified in negatively stained preparations by its dis- 
tinctive fibrous appearance (Pl. 2, fig. 3). Most major contamination detectable in the electron microscope, however, was removed by centrifugation on the sucrose density gradients; this purification of mitochondria was also indicated by the increased rate of oxidation of succinate (Fig. I).

Three mitochondrial profiles were seen in about equal numbers in thin sections of the

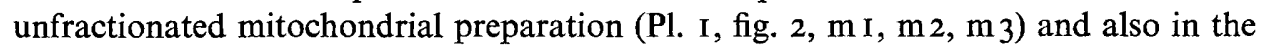
purified mitochondrial fraction collected from sucrose gradients. This heterogeneity in mitochondrial appearance probably was due, in part, to damage incurred during preparation. This interpretation is supported by the relatively low respiratory control ratios (compared with intact rat liver mitochondria) and high $\mathrm{Mg}$-ATPase activity of mitochondria from Neurospora crassa (Tables 3, 4). The structure of mitochondria from hyphal cells appeared indistinguishable from mitochondria isolated from conidia or germinating conidia by the grinding procedure used.

Isolated mitochondria of Neurospora crassa, negatively stained with PTA, contained small particles (80-90 A diameter) apparently associated with the inner mitochondrial membranes; the outer membrane, at least in some profiles, appeared relatively smooth (PI. 2, fig. 4). This observation agrees with that reported previously by Stoeckenius (I963). However, thin strands of membranes with attached particles were seen much less frequently than in negatively stained preparations of rat liver mitochondria (unpublished observations). It is possible that mitochondria of $N$. crassa are less susceptible to disruption during negative staining than are rat liver mitochondria; disruption of the membrane may be necessary for the particles to be visible in the electron microscope (Sjostrand, Andersson-Cedergren \& Karlsson, I964).

\title{
Table I. Requirements for oxidative phosphorylation*
}

\begin{abstract}
The complete reaction mixture contained Io mM-succinate, $125 \mathrm{~mm}$-sucrose, $10 \mathrm{mM}-\mathrm{MgCl}_{2}$, Io mM-potassium phosphate (pH 6.9), I.5 mM-EDTA, I mM-ADP, 20 mM-glucose, $150 \mathrm{~K} . \mathrm{M}$. units hexokinase $/ \mathrm{ml}$., $3.15 \mathrm{mg}$. mitochondrial protein. Final volume $2.0 \mathrm{ml}$. Omission of sucrose, bovine serum albumin or EDTA was not complete since concentrations of $25 \mathrm{~mm}$, $0.15 \mathrm{mg} . / \mathrm{ml}$. and $0.5 \mathrm{~mm}$, respectively, resulted from their addition with the mitochondrial preparation $\left(0.2 \mathrm{ml}\right.$.). Uptake of $\mathrm{O}_{2}$ was measured manometrically at $25^{\circ}$ for $20 \mathrm{~min}$.
\end{abstract}

Assay system
Complete
- sucrose
- BSA
- EDTA
- Mg++
- ADP
- Pi
- hexokinase and glucose
- succinate
- mitochondria

$\begin{array}{ccc}\mu \text { Uptake/mg. protein } / \mathrm{hr} & \\ 6.2 & \mu \text { atoms } \mathrm{O}_{2} & \text { P:O ratio } \\ 6.4 & 5 \cdot 0 & \mathrm{I} \cdot 3 \\ 6.5 & 5 \cdot 8 & \mathrm{I} \cdot \mathrm{I} \\ 7 \cdot 9 & 7 \cdot 2 & 0.9 \\ 0.9 & 6 \cdot 8 & \mathrm{I} \cdot 2 \\ 0 & 5 \cdot 7 & 0.2 \\ 0 & 4 \cdot 4 & 0 \\ 2 \cdot 2 & 2 \cdot 3 & 0 \\ 0 & 6 \cdot 9 & 0.3 \\ 0 & 0 & 0 \\ 0 & 0 & 0\end{array}$

* Succinate was used as substrate.

\section{Biochemical properties of Neurospora mitochondria}

Oxidative phosphorylation. Table I shows that mitochondria isolated from Neurospora crassa by the procedure outlined here coupled the phosphorylation of ADP to ATP to the oxidation of succinate. The data indicate that additions of substrate, $\mathrm{Mg}^{2+}$ 
$\mathrm{ADP}, \mathrm{Pi}$, hexokinase and glucose to the reaction medium were essential for this activity. In respect of these requirements, mitochondria from $N$. crassa are similar to mitochondria from mammalian tissues. The authors discovered in preliminary experiments that sucrose + bovine serum albumin +EDTA in the preparation medium facilitated the isolation of biochemically active mitochondria from $N$. crassa. These compounds were therefore used in the medium in which the mitochondria were suspended and were added as part of the mitochondrial suspension to the oxidative phosphorylation reaction mixture. As a result, failure to make further additions of these compounds affected oxidative phosphorylation only slightly (see Table $\mathrm{I}$ ). The $\mathrm{P}: \mathrm{O}$ ratios obtained in different experiments with succinate as substrate ranged from about $0 \cdot 7$ to $\mathrm{I} \cdot 3$.

Table 2. Effect of respiratory inhibitors and uncouplers on oxidative phosphorylation*

\begin{abstract}
Reaction mixture was that given in Table I but the final volume was I $\mathrm{ml}$. and the following additions were made where indicated: DNP, $0.4 \mathrm{~mm}$; antimycin $\mathrm{A}, 0.5 \mu \mathrm{g} . / \mathrm{ml}$; oligomycin, $5 \mu \mathrm{g} . / \mathrm{ml}$; $\mathrm{KCN}$, I mM; malonate, $20 \mathrm{mM}$; oleate, $\mathrm{O} . \mathrm{I} \mathrm{mM}$; atractylate, $0 . \mathrm{I} \mathrm{mM}$; $p$ - $\mathrm{F}_{3} \mathrm{MeOCCP}, \mathrm{I} \mu \mathrm{M} ; m$-Cl-CCP, $2.5 \mu \mathrm{M}$; gramicidin, $6 \mu \mathrm{M}$. Between 3 and $4 \mathrm{mg}$. mitochondrial protein were added in each experiment, which were run for $20-40 \mathrm{~min}$. at $25^{\circ}$, with $5 \mathrm{ml}$. volume manometric vessels.
\end{abstract}

Assay system
Control-no additions
+ Antimycin A
+ KCN
+ Malonate
+ Oligomycin
+ DNP
+ Oleate
+ Atractylate
+ $p$ - F $_{3} \mathrm{O}-\mathrm{CCP}$
+ $m$-Cl-CCP
+ Gramicidin

$\begin{array}{ccc}\overbrace{\mu \text { moles Pi }}^{\text {Uptake/mg. protein } / \mathrm{hr}} & \\ 5.9 & \mu \text { atoms } \mathrm{O}_{2} & \mathrm{P}: \mathrm{O} \text { ratio } \\ 0 & 7 \cdot 2 & 0.82 \\ 0 & 0 & 0 \\ 0 & 0 & 0 \\ 0 & 0 & 0 \\ 0 & 5 \cdot 8 & 0 \\ 0 & 2.4 & 0 \\ 0 & 1.5 & 0 \\ \mathrm{I} \cdot 8 & 5.0 & 0 \\ 0.5 & 4.8 & 0.37 \\ 0.9 & 2.4 & 0.21 \\ & 3.7 & 0.25\end{array}$

* Succinate was used as substrate.

A number of compounds, at concentrations which commonly uncouple or inhibit oxidative phosphorylation in mammalian mitochondria, also depressed the $\mathrm{P}: \mathrm{O}$ ratios obtained with mitochondria from Neurospora crassa when succinate was the substrate (Table 2). In the presence of antimycin A, KCN or malonate, no oxygen uptake or phosphorylation was observed. Oligomycin, 2,4-dinitrophenol (DNP), oleate and atractylate were effective uncouplers of the phosphorylation of ADP to ATP and oxygen consumption was decreased by various degrees with these reagents. With gramicidin, carbonyl cyanide- $m$-chlorophenylhydrazone ( $m-\mathrm{Cl}-\mathrm{CCP})$, and carbonyl cyanide- $p$-trifluoromethoxyphenylhydrazone $\left(p-\mathrm{CF}_{3} \mathrm{O}-\mathrm{CCP}\right)$ in the reaction medium, the $\mathrm{P}: \mathrm{O}$ ratios were decreased.

Table 3 shows that mitochondria of Neurospora crassa isolated from 2-day hyphae by the grinding procedure outlined here, coupled phosphorylation to the oxidation of the seven substrates which were tested. In some cases, the P:O ratios were somewhat less than theoretical values; however, to our knowledge these data represent the first detailed study of mitochondria capable of carrying out oxidative phosphorylation from fungal cells other than yeasts. Table 3 shows also that some respiratory control was 
observed with the isolated mitochondria of $N$. crassa. The respiratory control ratios were much lower than those reported for mammalian mitochondria where ratios of 4-10 are not uncommon. Also the respiratory control ratios obtained for mitochondria from $N$. crassa were in general somewhat lower than those reported for yeast mitochondria (Ohnishi, et al., 1966). The mitochondria of $N$. crassa responded to the addition of the ADP to about the same extent as 'loosely coupled' mammalian mitochondria.

Cytochrome content. Figure 2 shows the difference spectrum (reduced-oxidized) of the cytochrome in mitochondria from 2-day hyphae. Characteristic peaks at 605, 445, 562 and a shoulder at $553 \mathrm{~m} \mu$ indicated the presence of cytochromes $a_{1}, a_{3}, b$ and $c$, respectively. Quantitatively these cytochromes were in the ratio about I:I:I:I although cytochrome $c$ was slightly lower than the others.

\title{
Table 3. Oxidative phosphorylation and respiratory control of Neurospora mitochondria using various substrates
}

\begin{abstract}
A. Oxidative phosphorylation. The reaction mixtures were as in Table I with the substrates varied as follows: Io mM-succinate; $10 \mathrm{~mm}$-citrate, -isocitrate, - $\alpha$-ketoglutarate, -pyruvate + 2.5 mM-malate (all plus I mM-NAD); $10 \mathrm{mM}-N A D H_{2} ; 25 \mathrm{~mm}$-ascorbate $+0.3 \mathrm{~mm}$ TMPD. Between 3 and $7 \mathrm{mg}$. mitochondrial protein were added in each experiment which was run for $10-80 \mathrm{~min}$. (depending on substrate) at $25^{\circ}$.

B. Respiratory control. The reaction mixtures contained, in a total volume of $2 \mathrm{ml}$.: sucrose, $125 \mathrm{~mm}$ (or 106. $3 \mathrm{~mm}$ ); bovine serum albumin, 3. $15 \mathrm{mg}$. $/ \mathrm{ml}$. (or $3.04 \mathrm{mg}$. $/ \mathrm{ml}$.); EDTA,

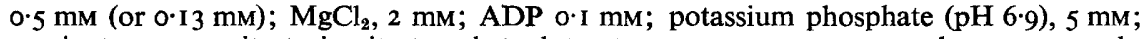
succinate, Io mM; citrate, isocitrate, $\alpha$-ketoglutarate or pyruvate $+2.5 \mathrm{~mm}$ malate, 10 mM each, all + I mM-NAD; $\mathrm{NADH}_{2}$, $10 \mathrm{~mm}$; ascorbate, $25 \mathrm{~mm}$. TMPD, $0.3 \mathrm{~mm}$. The figures in brackets reflect the lower quantities of mitochondria added in the case of ascorbate and $\mathrm{NADH}_{2}$ oxidation. Between $\mathrm{I}$ and $8 \mathrm{mg}$. mitochondrial protein (depending on substrate) were added. Rate of $\mathrm{O}_{2}$ uptake was measured polarographically (Clark oxygen electrode) and at $25^{\circ}$ calculated as $\mathrm{m} \mu$ atoms $\mathrm{O}_{2}$ taken up $/ \mathrm{mg}$. protein $/ \mathrm{min}$.
\end{abstract}

\begin{tabular}{|c|c|c|c|c|}
\hline \multirow[b]{2}{*}{ Substrate } & \multicolumn{2}{|c|}{ Uptake per/mg. protein $/ \mathrm{hr}$} & \multirow[b]{2}{*}{$\begin{array}{l}\mathbf{P}: \mathbf{O} \\
\text { ratio }\end{array}$} & \multirow[b]{2}{*}{$\begin{array}{l}\text { R.C. } \\
\text { ratio* }\end{array}$} \\
\hline & $\mu$ moles $\mathrm{Pi}$ & $\mu$ atoms $\mathrm{O}_{2}$ & & \\
\hline Ascorbate + TMPD & $5 \cdot 2$ & 8.4 & 0.6 & $I \cdot 36$ \\
\hline $\mathrm{NADH}_{2}$ & $5 \cdot 8$ & $6 \cdot 9$ & 0.8 & $I \cdot I 5$ \\
\hline Succinate & $7 \cdot 5$ & $5 \cdot 0$ & $\mathrm{I} \cdot 5$ & $I \cdot 70$ \\
\hline Pyruvate (malate) & 0.8 & 0.4 & I.9 & $2 \cdot 30$ \\
\hline Citrate & $7 \cdot 6$ & $2 \cdot 6$ & $3 \cdot 0$ & $2 \cdot 00$ \\
\hline Isocitrate & $2 \cdot 4$ & $I \cdot 5$ & $\mathrm{I} \cdot 6$ & $I \cdot 70$ \\
\hline$\alpha$-Ketoglutarate & $4 \cdot 7$ & $I \cdot 4$ & $3 \cdot 3$ & 2.00 \\
\hline
\end{tabular}

${ }^{*}$ Respiratory control ratio $=\frac{\text { rate of } \mathrm{O}_{2} \text { uptake in presence of added ADP }}{\text { rate of } \mathrm{O}_{2} \text { uptake in absence of added ADP }}$.

Activities related to oxidative phosphorylation. A number of enzymic activities associated with the oxidative phosphorylation reactions of mammalian mitochondria were assayed to determine whether these could be detected in mitochondria from Neurospora crassa. The 'partial reactions' of oxidative phosphorylation which were surveyed included $\mathrm{Mg}^{2+}$ - and DNP-stimulated ATPase, ADP-Pi exchange activity, and ion accumulation. Mitochondria isolated from 2-day hyphae were used in these studies. Table 4 shows that ATPase, ATP-Pi exchange and ion accumulation activities could be measured in mitochondria from $N$. crassa. The rather low ATPase activity was stimulated by $\mathrm{Mg}^{2+}$ but not by DNP, and was inhibited by oligomycin. Results from other 
experiments showed that the $\mathrm{Mg}^{2+}$-stimulated ATPase in mitochondria from conidia and germinating conidia was 4-5 times higher than that reported here. The ATP-Pi exchange activity was sensitive to DNP and to oligomicin (Table 4) suggesting that this activity was related to oxidative phosphorylation. Accumulation of ${ }^{45} \mathrm{Ca}^{2+}$ by $N$. crassa mitochondria was supported by substrate oxidation, but the rate of uptake was considerably slower than that observed with intact rat liver mitochondria (Lehninger, Rossi \& Greenawalt, 1963; Rossi \& Lehninger, 1963). This activity, as in rat liver mitochondria, appeared to be respiration-dependent since $\mathrm{KCN}$ inhibited the reaction (Table 4). A slow rate of $\mathrm{Ca}^{2+}$ accumulation was supported by ATP; this appeared to be insensitive to $\mathrm{KCN}$ and to oligomycin. The mitochondria from $N$. crassa

\section{Table 4. Activities related to oxidative phosphorylation}

A. ATPase activity of isolated mitochondria. The reaction mixtures contained, in a total volume of $\mathrm{I} \mathrm{ml}$, the following: $15 \mathrm{mM}-\mathrm{ATP},(\mathrm{pH} 7) ; \mathrm{I} \cdot 2-2.6 \mathrm{mg}$. mitochondrial protein; and, as indicated: $0.4 \mathrm{mM}-\mathrm{DNP} ; 3 \mathrm{~mm}-\mathrm{MgCl}_{2} ; 10 \mu \mathrm{g}$. oligomycin $/ \mathrm{ml}$. The reactions were run for I $5 \mathrm{~min}$. $\left(\mathrm{Mg}^{2+}\right)$ or $30 \mathrm{~min}$. (DNP) at $25^{\circ}$.

B. ATP ${ }^{32} \mathrm{Pi}$ exchange activity of isolated mitochondria. The reaction mixtures contained, in a final volume of $\mathrm{I} \mathrm{ml}$., the following: $15 \mathrm{~mm}-\mathrm{ATP},(\mathrm{pH} 7)$; $\mathrm{I} \mathrm{mM-} \mathrm{MgCl}_{2}$; $10 \mathrm{mM}$-potassium phosphate, ${ }^{32} \mathrm{P}(\mathrm{pH} 6.9) ; \mathrm{I} \cdot 2-2.6 \mathrm{mg}$. mitochondrial protein; and, as indicated: $0.4 \mathrm{mM}$-DNP; Io $\mu \mathrm{g}$-oligomycin $/ \mathrm{ml}$. The reactions were run for $30 \mathrm{~min}$. at $25^{\circ}$.

C. Uptake of $\mathrm{Ca}^{2+}$ by isolated mitochondria. The reaction mixtures contained, in a final volume of $5 \mathrm{ml}$., the following: Io mM-tris- $\mathrm{HCl}(\mathrm{pH} 7) ; 80 \mathrm{~mm}-\mathrm{NaCl}$; $10 \mathrm{mM}-\mathrm{MgCl}_{2} ; 4 \mathrm{mM}-$ potassium phosphate $(\mathrm{pH} 7) ; 3 \mathrm{mM}^{-45} \mathrm{CaCl}_{2} ; 3$ mM-ATP (succinate-supported uptake) or $15 \mathrm{~mm}$-ATP (ATP-supported uptake); 4-8 mg. mitochondrial protein; and the following, where indicated: Io mM-succinate; $\mathrm{mM}-\mathrm{KCN}$; $10 \mu \mathrm{g}$. oligomycin $/ 5 \mathrm{ml}$. The reactions were run for $20 \mathrm{~min}$. at $30^{\circ}$.

\begin{tabular}{|c|c|c|c|}
\hline \multicolumn{2}{|l|}{ ATPase } & \multicolumn{2}{|c|}{ ATP_32Pi Exchange } \\
\hline System & $\begin{array}{l}\text { Spec. } \\
\text { act.* }\end{array}$ & System & $\begin{array}{l}\text { Spec. } \\
\text { Act. } \dagger\end{array}$ \\
\hline I. Control & 0.07 & I. Complete & I 54 \\
\hline 2. + DNP & 0.05 & 2. + DNP & 0 \\
\hline $\begin{array}{l}\text { 3. +DNP+oligomycin } \\
\text { 4. }+\mathbf{M g}^{2+} \\
\text { 5. }+\mathbf{M g}^{2+}+\text { oligomycin }\end{array}$ & $\begin{array}{l}0.02 \\
1 \cdot 66 \\
0 \cdot 29\end{array}$ & 3. + Oligomycin & 0 \\
\hline
\end{tabular}

* $\mu$ moles $\mathrm{Pi} / \mathrm{mg}$. protein $/ \mathrm{hr}$.

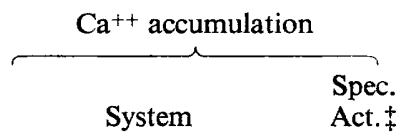

A. substrate-supported

$$
\begin{array}{ll}
\text { I. complete (succinate) } & 1 \cdot 0 \\
\text { 2. + KCN } & 0.3 \\
\text { 3. + Oligomycin } & 0.9
\end{array}
$$

B. ATP-supported

$\begin{array}{ll}\text { I. Complete (ATP) } & 0.4 \\ \text { 2. + KCN } & 0.4 \\ \text { 3. + Oligomycin } & 0.4\end{array}$

$\dagger \mu$ moles $\mathrm{AT}^{32} \mathrm{P} / \mathrm{mg}$. protein $/ \mathrm{hr}$.

$\ddagger \mu$ moles $\mathrm{Ca}^{2+} / \mathrm{mg}$. protein $/ \mathrm{hr}$.

showed no capacity to accumulate either $\mathrm{Mg}^{2+}$ or $\mathrm{Sr}^{2+}$, which are readily taken up by mammalian mitochondria (Brierley, Bachmann \& Green, I962: Carafoli, Weiland \& Lehninger, 1965). In addition to these reactions, some ATP-ADP exchange activity and a slow rate of incorporation of leucine- ${ }^{14} \mathrm{C}$ by the mitochondria were detected.

Density gradient fractionation. It is clear that mitochondria isolated from 2-day hyphae of Neurospora crassa by the procedure described, were capable of carrying out biochemical reactions typical of mammalian mitochondria. However, the low respiratory control ratios, the presence of $\mathrm{Mg}^{2+}$-ATPase and absence of DNP-ATPase, and the variation in mitochondrial profiles seen in the electron microscope (Pl. I, fig. 2) suggested that the mitochondria were damaged to some extent during preparation. Furthermore, it was apparent from electron microscopic examination that the crude 
mitochondrial preparation was contaminated with other subcellular material, especially cell wall fragments. It was of interest, therefore, to determine whether a more homogenous mitochondrial fraction might be separated on sucrose density gradients.

Centrifugation of the crude mitochondrial preparation on a linear sucrose density gradient produced four fractions. Two major bands were observed on the gradient, a distinct, orange 'mitochondrial' fraction and lighter, more diffuse 'submitochondrial' fraction. A third, very faint band which contained very little of the total protein placed on the gradient formed above the sub-mitochondrial fraction. The fourth fraction sedimented as a pellet at the bottom of the tube. The bands were collected dropwise from the tubes in 25-drop fractions and assayed for enzymic activities and for cytochromes. Difference spectra showed that both the mitochondrial and submitochondrial

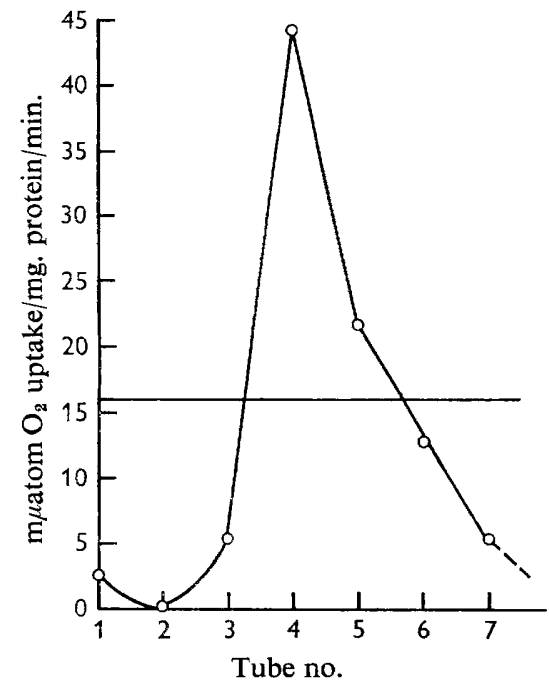

Fig. I

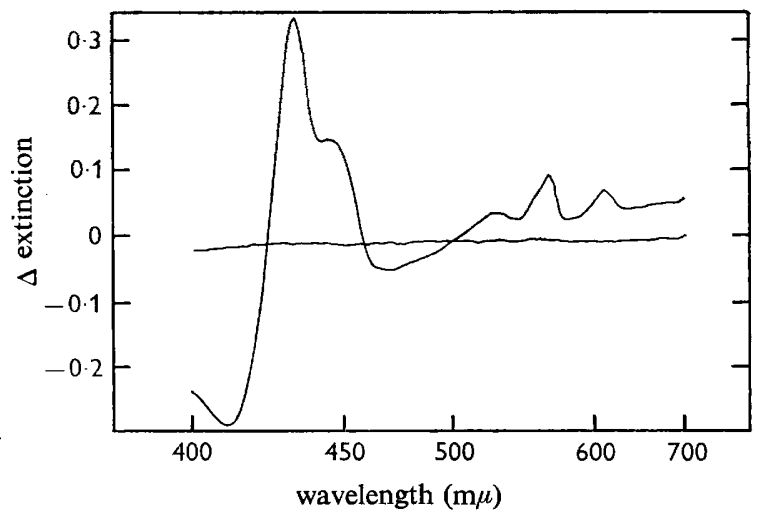

Fig. 2

Fig. I. Distribution of the succinoxidase activity in the mitochondrial fractions obtained from the sucrose density gradients. Rate of $\mathrm{O}_{2}$ uptake was determined polarographically as described in legend for Table 3. The rate of oxidation of succinate by the unfractionated mitochondrial preparation is indicated by the horizontal line.

Fig. 2. Difference spectra (reduced minus oxidized) of Neurospora crassa mitochondria. Mitochondria (27 mg. protein) were added to each of two cuvettes in a final volume of $3 \mathrm{ml}$. The reduced spectrum was obtained by adding excess $\mathrm{Na}_{2} \mathrm{~S}_{2} \mathrm{O}_{4}$ to one cuvette following the method of King et al. (1964).

fractions contained cytochromes and that both were capable of oxidizing succinate, NADH and ascorbate +TMPD. The submitochondrial fraction oxidized NADH more rapidly than the mitochondrial fraction but the reverse was true with succinate as substrate. The relative rates of succinate oxidation by the mitochondrial fraction (collected in tubes 3 and 4) and the submitochondrial fraction (tubes 5 and 6) are shown in Fig. 2. Ascorbate + TMPD was oxidized by both fractions at rates intermediate to the oxidation of NADH and succinate. Respiratory control, although low, was present only in the mitochondrial fraction.

The pellet, mitochondrial and submitochondrial fractions were negatively stained with PTA and examined in the electron microscope. The pellet contained large frag- 
ments of cell wall, some mitochondria, and unidentified cellular material. Mostly intact mitochondria were present in the mitochondrial band and the submitochondrial fraction contained membranous profiles, many of which resembled mitochondrial fragments. Only limited material from the uppermost band was available for examination but this fraction appeared to contain primarily small membranous vesicles (possibly microsomal membranes) and very small pieces of cell wall.

\section{DISCUSSION}

Specific conditions were found to be required to isolate biochemically competent mitochondria from hyphae of Neurospora crassa. The inclusion of bovine serum albumin and the omision of phosphate (which may preclude mitochondrial swelling and the uncoupling of phosphorylation) in the isolation medium enabled the isolation of a mitochondrial fraction from $N$. crass $a$ which was capable of performing oxidative phosphorylation. Bovine serum albumin was shown by Wojtczak \& Wojtczak (1960) to be beneficial in the isolation of functional mitochondria from insects, and they showed that it removed fatty acids which uncoupled oxidative phosphorylation; it is possible that the albumin performs the same function in the preparations of mitochondria from $N$. crassa described here. During the present work it was observed that the first crude mitochondrial fraction, i.e. the mitochondria in the supernatant fluid of the first centrifugation at I500g, was unable to form ATP although substrates were oxidized. However, when the mitochondria were subsequently centrifuged from the crude supernatant fluid (at $8000 \mathrm{~g}$ ) they did phosphorylate ADP to ATP, even when the supernatant fluid from the $8000 \mathrm{~g}$ centrifugation was added back to the mitochondria. Apparently an uncoupling phenomenon occurred before the physical separation of the mitochondria from the supernatant fluid fraction. This uncoupling action of the crude supernatant fluid fraction was not investigated further, it may be related to the requirement for serum albumin in the preparation medium.

From Tables $I$ and 2 it is evident that the oxidation of succinate by the mitochondrial fraction isolated from Neurospora crassa was linked to phosphorylation with characteristics similar to those shown by mitochondria isolated from many other organisms. The data in Tables 3 and 4 show that $N$. crassa mitochondria coupled phosphorylation to the oxidation of a number of substrates, exhibited some respiratory control, and carried out a number of enzymic activities linked energetically to oxidative phosphorylation.

Biochemical and ultrastructural evidence suggest that the mitochondria in the crude preparation were damaged to some extent in the isolation procedure. However, it is possible that the uncoupling phenomenon mentioned above is not completely reversible and affects the biochemical activities of the mitochondria in the crude preparation. The respiratory control ratios recorded for Neurospora crassa mitochondria were low as compared with those of mammalian mitochondria, but were comparable with those reported for yeast mitochondria (Ohnishi et al. 1966). Mitochondria have been isolated from $N$. crassa by milder treatment (Greenawalt, Hall, \& Wallis, 1967) with only a slight increase in respiratory control ratios.

Fractionation of the mitochondrial preparation on sucrose density gradients enabled the collection of a purer mitochondrial fraction since cell wall contamination and fragmented mitochondria were separated from the major mitochondrial band. The presence of cytochromes $a+a_{3}, b$ and $c$ indicated that the submitochondrial fraction 
was most likely derived from the mitochondria. Respiratory control ratios were recorded only with the mitochondrial fraction.

The authors are indebted to Mr G. Decker and Miss Paula Carrico for expert technical assistance. The authors also wish to thank Dr A. L. Lehninger for critically reading the manuscript. This work was supported in part by Research Grant GM-I 2 I 25 from the National Institutes of Health, United States Public Health Service.

\section{REFERENCES}

Brierley, G. P., BachmanN, E. \& Green, D. E. (1962). Active transport of inorganic phosphate and magnesium ions by beef heart mitochondria. Proc. natn. Acad. Sci., U.S.A. 48, 1928.

BRITTEN, R. J. \& RoBERTs, R. B. (1960). High-resolution density gradient sedimentation analysis. Science, N.Y. 131, 32.

Carafoli, E., Weiland, S. \& Lehninger, A. L. (1965). Active accumulation of $\mathrm{Sr}^{2+}$ by rat-liver mitochondria. I. General features. Biochim. biophys. Acta $97,88$.

Chance, B. \& Williams, G. R. (1955). Respiratory enzymes in oxidative phosphorylation. I. Kinetics of oxygen utilization. J. biol. Chem. 217, 383 .

COOPER, C. \& LeHNiNGer, A. L. (I957). Oxidative phosphorylation by an enzyme complex from extracts of mitochondria. IV. Adenosinetriphosphatase activity. J. biol. Chem. 224, 547.

Duell, E. A., Inoue, S. \& UtTer, M. F. (1964). Isolation and properties of intact mitochondria from spheroplasts of yeast. $J$. Bact. 88, 1762 .

GoA, J. (1953). A microbiuret method for protein determination. Determination of total protein in cerebrospinal fluid. Scand. J. clin. Lab. Invest. 5, 218.

GoMORI, G. (1942). A modification of the colorimetric phosphorous determination for use with the photoelectric colorimeter. J. Lab. clin. Med. $27,955$.

Greenawalt, J. W., Hall, D. O., \& Wallis O. C. (I967). Preparation and properties of Neurospora mitochondria. Meth. Enzym. (in press).

Hall, D. O. \& Greenawalt, J. W. (1964). Oxidative phosphorylation by isolated mitochondria of Neurospora crassa. Biochem. biophys. Res. Commun. 17, 565.

VAN. ITERSON, W. (I965). Symposium on the fine structure and replication of bacteria and their parts. II. Bacterial cytoplasm. Bact. Rev. 29, 299.

KING, T. E., NICKEL, K. S. \& JENSEN, D. R. (1964). Iron, copper, cytochrome, and lipid contents of heart muscle preparation and heart mitochondria. J. biol. Chem. 239, 1989.

Lehninger, A. L., Rossi, C. S. \& Greenawalt, J. W. (1963). Respiration-dependent accumulation of inorganic phosphate and $\mathrm{Ca}^{++}$by rat liver mitochondria. Biochem. biophys. Res. Commun. Io, 444 .

Lowry, O. H., Rosebrough, J. N. Farr, A. L. \& Randall, R. J. (I95I). Protein measurement with the Folin phenol reagent. J. biol. Chem. 193, 265.

LuCK, D. J. L. (1963). Formation of mitochondria in Neurospora crassa. A quantitative radioautographic study. J. Cell Biol. I6, 483.

LUFT, J. H. (I96I). Improvements in epoxy resin embedding methods. J. biophys. biochem. Cytol. 9, 409.

Moore, R. T. \& MCAlear, J. H. (1963). Fine structure of Mycota. 9. Fungal mitochondria. $J$. Ultrastruct. Res. 8, I44.

NoRTH, R. J. (1961). Method for revealing the membrane systems in micro-organisms. Nature, Lond. 190, 1215.

Ohnishi, T., Kawaguchi, K. \& Hagihara, B. (I966). Preparation and some properties of yeast mitochondria. J. biol. Chem. 24r, 1797.

Rossi, C. S. \& LeHNINGER, A. L. (1963). Stoichiometric relationships between accumulation of ions by mitochondria and the energy-coupling sites in the respiratory chain. Biochem. Z. 338, 698.

ShatKIN, A. J. \& TATUM, E. L. (1959). Electron microscopy of Neurospora crassa mycelia. J. biophys. biochem. Cytol. 6, 423. 
Sjöstrand, F. S., ANdersson-Cedergren, E. and Karlsson, U. (1964). Myelin-like figures formed from mitochondrial material. Nature, Lond. 202, 1075.

Slater, E. C. \& Holton, F. A. (1954). Oxidative phosphorylation coupled with the oxidation of $\alpha$-ketoglutarate by heart-muscle sarcosomes. 2. Phosphorus:oxygen ratio. Biochem. J. 56, 28.

Stoeckenius, W. (1963). Some observations of negatively stained mitochondria. J. Cell Biol. 17, 443.

TRUMAN, D. E. S. \& KorNer, A. (I962). Incorporation of amino acids into the protein of isolated mitochondria. Biochem. J. 83, 588.

Tsuda, S. (1956). Electron microscopical studies of ultrathin sections in Penicillium chrysogenum. J. Bact. 7r, 450.

VItols, E. \& LinNANE, A. W. (196I). Studies on the oxidative metabolism of Saccharomyces cerevisiae. I I. Morphology \& oxidative phosphorylation capacity of mitochondria \& derived particles from baker's yeast. J. biophys. biochem. Cytol. 9, 701.

Vogel, H. J. (1956). A convenient growth medium for Neurospora (medium N). Microbiol. Genet. Bull. 13, 42.

Wadkins, C. L. \& Lehninger, A. L. (1963). Preparation and assay of phosphorylating submitochondrial particles. Meth. Enzym. 6, 265.

WAINWRIGHT, S. D. (1959). On the development of increased tryptophan synthetase enzyme activity by cell-free extracts of Neurospora crassa. Can. J. Biochem. Physiol. 37, 1417.

WeIss, B. (1965). An electron microscope and biochemical study of Neurospora crassa during development. J. gen. Microbiol. 39, 85.

WOJTCZAK, L. \& WoJTCZAK, A. B. (1960). Uncoupling of oxidative phosphorylation and inhibition of ATP-P $P_{1}$ exchange by a substance from insect mitochondria. Biochim. biophys. Acta 39, 277.

\section{EXPLANATION OF PLATES}

Plate I

Fig. x. Thin section of a 2-day hypha of Neurospora crassa. Nuclei (N) and mitochondria (m) including the cristae are clearly visible. The cell wall $(\mathrm{CW})$ is only lightly stained. Fixed with $\mathrm{KMnO}_{4}$ and uranyl acetate. Unstained. $\times 26,000$.

Fig. 2. Mitochondria isolated from 2-day hyphae of Neurospora crassa. Three profiles $\left(\mathrm{m}_{1}, \mathrm{~m}_{2}, \mathrm{~m}_{3}\right)$ can be seen. Fixed with $\mathrm{KMnO}_{4}+$ uranyl acetate. Unstained. $\times 20,000$.

\section{Plate 2}

Fig. 3. A large fragment of cell wall contaminating the crude mitochondrial fraction. The distinct fibrous appearance of this material can be seen. Negatively-stained with potassium phosphotungstate (PTA), pH 6.5. $\times 60,000$.

Fig. 4. Isolated mitochondrion negatively stained with PTA, pH 6.5. The relatively smooth outer membrane $(\mathrm{OM})$ is partly disrupted and torn away from the mitochondrion. The inner membrane (IM) protrudes (left-centre of the micrograph) and has small (90 $\AA$ ) projecting particles associated with it. $\times 65,000$. Inset: enlargement of portion of inner membrane outlined by inked lines. The $90 \AA$ particles are clearly seen. $\times 140,000$. 


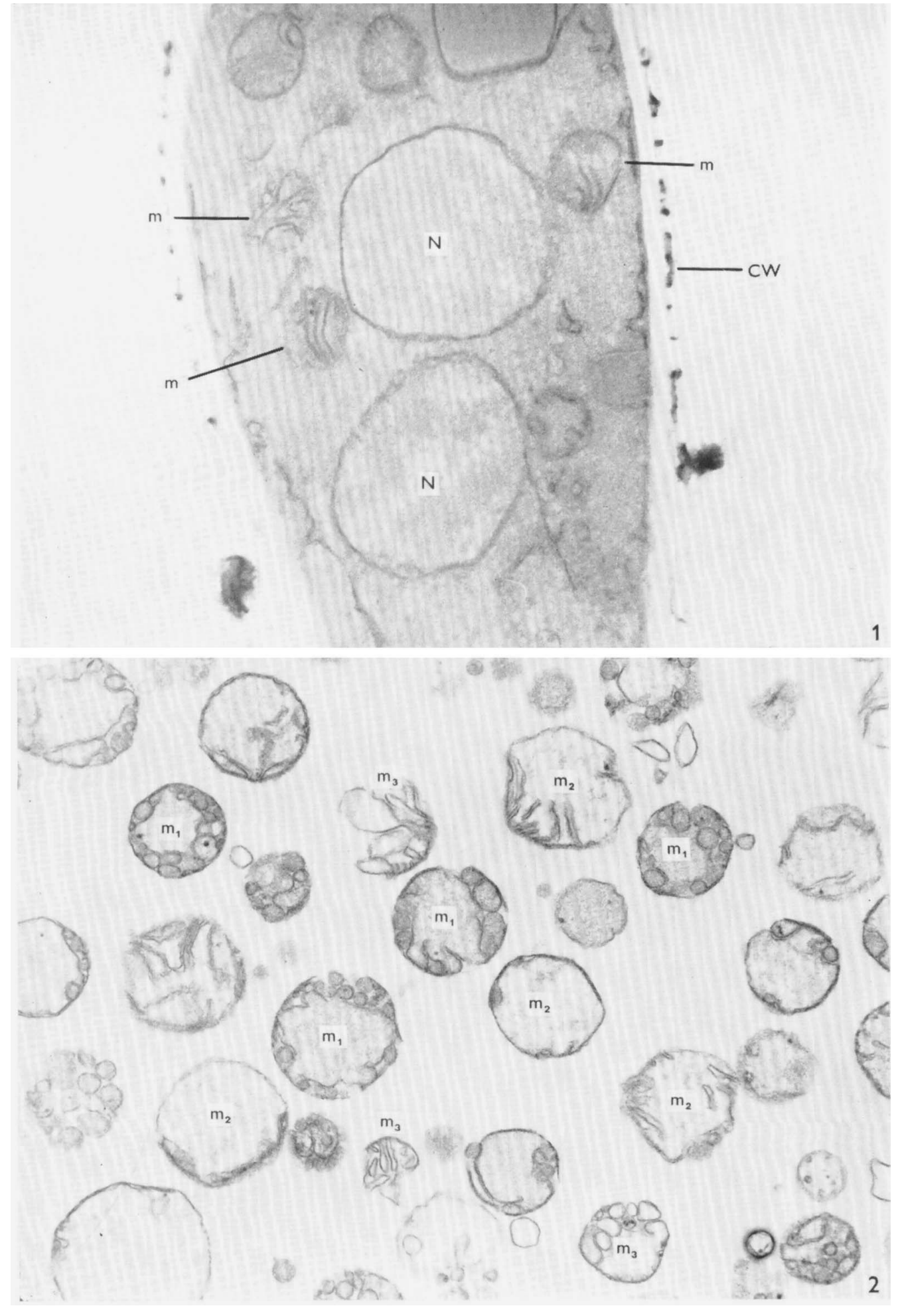



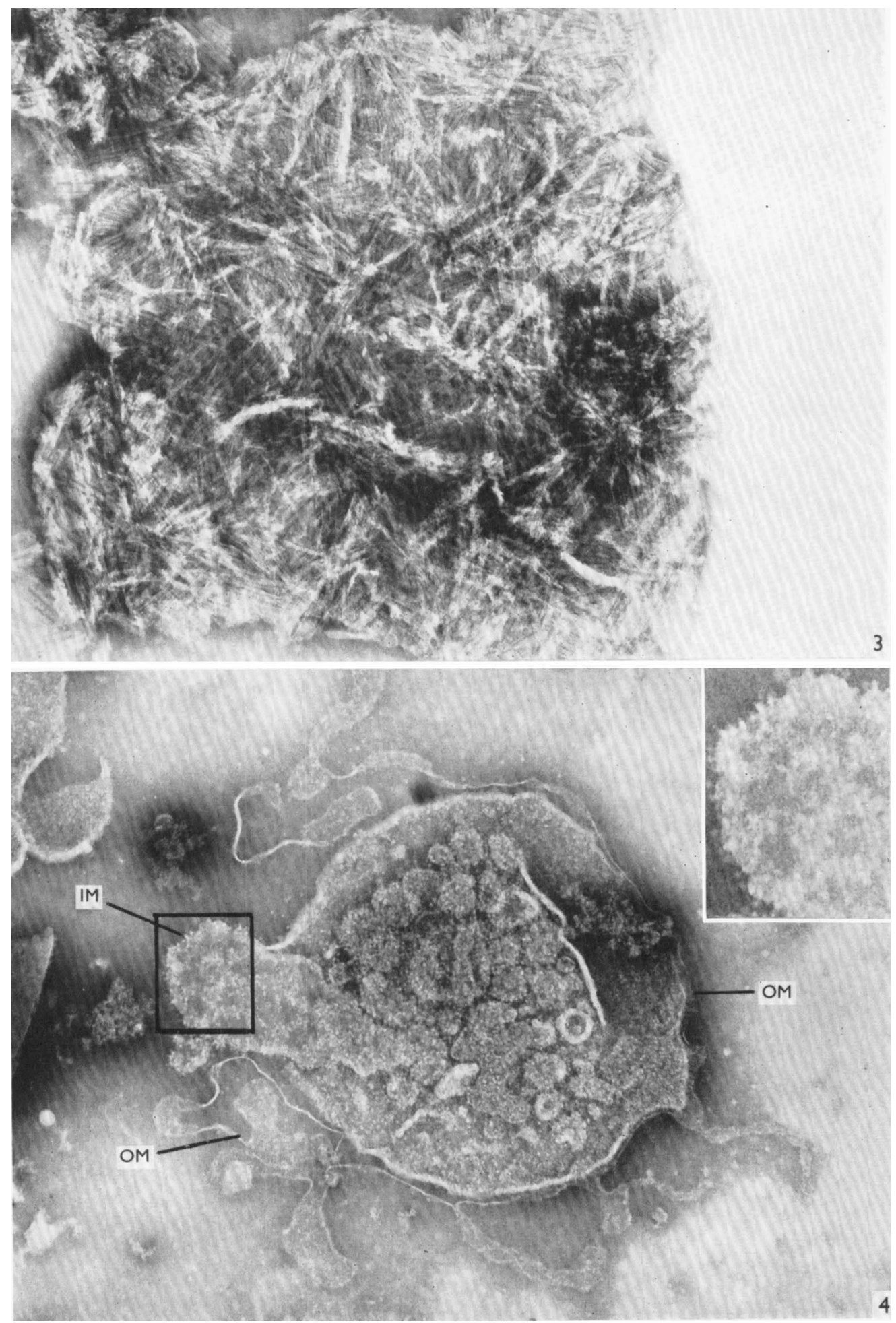

D. O. HALL AND J. W. GREENAWALT 